\title{
Factors affecting birth weight in sheep: maternal environment
}

\author{
D S Gardner, P J Buttery ${ }^{2}$, Z Daniel $^{2}$ and M E Symonds ${ }^{1}$
}

Centre for Reproduction and Early Life, Schools of Veterinary Medicine and Science, University of Nottingham, Sutton Bonington Campus, Sutton Bonington, Leicestershire LE12 5RD, UK, ${ }^{1}$ Human Development, University Hospital, Nottingham NG7 2UH, UK and ${ }^{2}$ Division of Nutritional Sciences, School of Biosciences, University of Nottingham, Sutton Bonington LE12 5RD, UK

Correspondence should be addressed to D Gardner; Email: david.gardner@nottingham.ac.uk

\begin{abstract}
Knowledge of factors affecting variation in birth weight is especially important given the relationship of birth weight to neonatal and adult health. The present study utilises two large contemporary datasets in sheep of differing breeds to explore factors that influence weight at term. For dataset one (Study 1; $n=154$ Blue-faced Leicester $\times$ Swaledale (Mule) and 87 Welsh Mountain ewes, 315 separate cases of birth weight), lamb birth weight as the outcome measure was related to maternal characteristics and individual energy intake of the ewe during specified periods of gestation, i.e. early (1-30 days; term $\sim 147$ days gestation), mid (31-80 days) or late (110-147 days) pregnancy. For dataset two (Study 2; $n=856$ Mule ewes and 5821 cases of birth weight), we investigated using multilevel modelling the influence of ewe weight, parity, barrenness, lamb sex, litter size, lamb mortality and year of birth on lamb birth weight. For a subset of these ewes $(n=283)$, the effect of the ewes' own birth weight was also examined. Interactions between combinations of variables were selectively investigated. Litter size, as expected, had the single greatest influence on birth weight with other significant effects being year of birth, maternal birth weight, maternal nutrition, sex of the lamb, ewe barrenness and maternal body composition at mating. The results of the present study have practical implications not only for sheep husbandry but also for the increased knowledge of factors that significantly influence variation in birth weight; as birth weight itself has become a significant predictor of later health outcomes.

Reproduction (2007) 133 297-307
\end{abstract}

\section{Introduction}

Knowledge of prenatal factors influencing the variation in birth weight is of primary importance with regard to immediate (neonatal) and longer term health and viability (Cogswell \& Yip 1995, Godfrey \& Barker 2001). In the agricultural industry, knowledge of the external, controllable factors that have a bearing on live weight at term is important in terms of agricultural economy. Theoretically, in all mammalian species, there is an 'optimum' birth weight in which an uncomplicated natural delivery can occur and neonatal survival is maximised; surrounded by a 'range of adequacy' where birth weight deviates from this optimum but neonates survive to reproductive age. Clearly, there is a strong genetic component accounting for some of the variation in birth weight as extremes beyond this range will, over time, be selected out: low birth weight is associated with increased neonatal mortality, high birth weight with complicated labour (dystocia) and maternal death (Alexander 1974).
However, the intrauterine environment exerts a more profound effect, with the lower end of a hypothetical adequate birth weight range most likely reflecting a poor intrauterine environment and the upper end inadvertent fetal growth promotion. Indeed, the importance of the environment in which the foetus develops, rather than its genome, on birth weight is best illustrated by embryo transfer studies in the human (Brooks et al. 1995), horse (Walton \& Hammond 1938, Giussani et al. 2003) and sheep (Dickinson et al. 1962). These original studies suggest that the largest influence on birth weight is the maternal environment, i.e. fetal genotype is 'maternally constrained'.

However, in the human, maternal weight (an environmental parameter) accounted for only $12 \%$ of the variation in birth weight (Brooks et al. 1995) indicating that many other factors influence eventual weight at term. Of these, in a polytocous species, such as the sheep, there are a number of well-known influences that significantly affect fetal growth and thus eventual birth weight, including litter size (reduced individual birth 
weight with increasing litter size) and sex of the offspring (males > females; Wallace 1948, Robinson et al. 1977, Black 1983). With regard to maternal nutrition influencing birth weight in the sheep, much information is available, but occasional discrepancies arise, most likely due to study-study differences between breed of sheep, sample size, definition of 'optimum' or $100 \%$ requirement (Wallace 1948, Russel 1971, Russel \& Foot 1973, Robinson 1977, Mellor \& Matheson 1979, Wallace et al. 1996, Heasman et al. 2000). Therefore, in the present study, we have in one dataset $>230$ ewes; $\sim 400$ cases of birth weight, in two distinct breeds of sheep in which the nutritional calculations are based upon the recommendations of the Agriculture and Food Research Council technical consultation on energy requirements of pregnant ewes (AFRC 1993). Furthermore, with detailed multilevel modelling, the magnitude of change in birth weight with alterations in maternal nutrition during specified periods of gestation, i.e. early versus late gestation, may be assessed with a significant degree of statistical power. It is hypothesised that late, as opposed to early, nutritional intake significantly effects birth weight in the sheep as this reflects the period of greatest absolute fetal growth (Mellor \& Matheson 1979).

Parity also affects fetal growth; the first-born being lighter than the second in humans (Cogswell \& Yip 1995, Ong et al. 2002) and sheep (Bradford 1972, Bradford et al. 1974), but whether this effect continues with increasing parity (i.e. $>2$ pregnancies) is not clear. This information is very important in the agricultural industry; for example, to know the number of seasons a ewe remains maximally productive in terms of lamb birth weight and when (i.e. after how many pregnancies) that productivity declines. The present study allows for such an examination over multiple pregnancies $(n=12)$ in sheep. In addition, while it is thought that a first pregnancy leaves a permanent uterine 'physiological imprint' that influences the second pregnancy, it is not known whether a ewe that experiences a subsequent barren season may have alterations to further successful pregnancies, in terms of lamb birth weight. This is specifically tested for the first time in the present study. In addition, given the increasing use of the sheep as a large animal model for the fetal programming of adult disease, where variations in birth weight are related to adult health outcomes, e.g. blood pressure and glucose tolerance (Edwards \& McMillen 2002, Armitage et al. 2004, Gardner et al. 2004, Gatford et al. 2004), then greater knowledge of the factors influencing that variation is important.

Hence, the present study conducts a statistical analysis of factors influencing birth weight in highland and lowland sheep using multilevel modelling to represent the hierarchical error structure implicit when regarding lambs born from a population of ewes. Explanatory factors tested in the analysis were: (1) maternally derived, e.g. weight, to what extent does maternal weight at mating affect birth weight?; breed, do highland versus lowland sheep exhibit production thrift?; parity, do birth weights rise linearly with increasing pregnancies?; body composition, does birth weight relate to low versus high body condition score?; energy intake, which gestation period is most important for influencing weight at birth?; barren season history, is the weight of the lamb less when the ewe has previously been barren?, (2) fetally derived, e.g. sex, males $>$ females?; fetal number, how much smaller are twins/triplets versus singles?; health, how much larger are lambs that survive versus those that don't? or (3) external to the sheep, e.g. year of birth, does year of itself have an independent effect on birth weight in the sheep. Interactions between combinations of variables were selectively investigated.

\section{Materials and Methods}

The present study describes retrospective data for two separate cohorts of sheep over an 11-year period. For the first cohort (Study 1), lamb birth weight as the outcome measure is related to maternal characteristics and individual energy intake of the ewe during any single pregnancy. In the second cohort (Study 2), lamb birth weight as the outcome measure is related to maternal characteristics during multiple pregnancies in the same ewe over a number of breeding seasons. For both studies, a population $(n=8)$ charrolais rams were used each year, with on average two rams being replaced each year.

\section{Study 1}

All procedures were performed under the UK Animals (Scientific Procedures) Act, 1986 and the general principles of laboratory animal care were followed (NIH 1985). In ewes, continuous (lamb birth weight, ewe weight, energy intake) and categorical (litter size, ewe parity, lamb sex, body condition score), data were recorded for all pregnancies over a preceding 11-year period from 1994 to 2005 at the University of Nottingham. Data incorporate separate nutritional trials in which pregnant ewes were singly housed over the course of gestation and daily nutritional intake accurately recorded as described previously (Heasman et al. 1998, Dandrea et al. 2001, Gardner et al. 2004, Fahey et al. 2005, Gopalakrishnan et al. 2005). Body condition score was assessed by a single experienced person according to Russel et al. (1969). For all separate studies, sheep were mated during their natural breeding season. After mating, sheep were individually housed and randomly assigned to receive either a control or a nutrient-restricted diet. The control diet provided at least $100 \%$ metabolisable energy (ME, $n=127$ ) requirements as defined by the Agricultural and Food Research Council (AFRC 1993). The nutrient-restricted (NR) diet provided $50-60 \%$ AFRC ME requirement and ewes were 
assigned to receive this reduced diet over specific periods of fetal development, i.e. days 0-95 $(n=27)$ or 30-80 ( $n=25), 30-70(n=72), 55-95(n=29), 85-115$ $(n=30)$ and 110 -term $(n=5)$. Whilst daily food intake was recorded, epoch averages were used for statistical analysis only. These were calculated as the average intake over early gestation (from days 1 to 30, term $\sim 147$ days), mid-gestation (average intake from days 31 to 80 ) or late gestation (average intake from days 110 to 147). These epochs in sheep coincide with preimplantation embryogenesis, placental proliferation and fetal hypertrophy respectively. At all other times, NR sheep received $100 \%$ ME requirement. The nutritional regimen for each ewe was adjusted accordingly throughout gestation to allow for ewe weight gain, fetal number and conceptus growth. At term, lambs delivered naturally and birth weights were recorded. For this study, a total of 154 Mule and 87 Welsh Mountain ewes (corresponding to 207 Mule and 108 Welsh Mountain lambs) were entered into the analysis.

\section{Study 2}

This study analysed data from the entire flock of a commercial sheep farming enterprise at the University of Nottingham, Sutton Bonington. In Mule ewes, continuous (lamb birth weight) and categorical (litter size, ewe parity, lamb sex, year of birth) data were recorded for all pregnancies over a preceding 11-year period from 1994 to 2005. In addition, further factors included in the analysis were health of the lamb (i.e. did the lamb die within 3 days of birth) and whether a ewe was barren in any particular year. From the barren season history, we derived variates corresponding to (a) the present number of consecutive barren seasons and (b) the number of seasons since a ewe was last barren. General farm animal husbandry procedures were adhered to, e.g. flushing of ewes prior to mating. At $\sim 90$ days gestation, the ewes were scanned for pregnancy confirmation and determination of fetal number. At this time, they were then sheared and group-housed indoors according to fetal number (max 20 per group) and fed the concentrate diet described previously, in addition to a proportion of dried and compacted grass nuts and ad libitum barley straw to maintain rumen function. The diet was adjusted according to fetal number and stage of gestation as shown in Table 1. Upon lambing, ewes were moved to individual pens and lambs weighed within $4 \mathrm{~h}$ of birth. Husbandry and nutritional procedures were identical over the 11-year period of the study with the same shepherd in charge of the sheep over this time. The dataset consisted of a total of 856 ewes with parities ranging from 1 to 11 , and 5821 records of lamb birth weight. Of this dataset, there were $n=694(12 \%)$ singles, $n=3598(62 \%)$ twins, $n=1320(23 \%)$ triplets and $n=101$ (2\%) quads valid cases. Lambs with missing data (108), typically birth weight, were excluded. Excluding litters for which there was no birth weight data, there were $n=2055$ valid cases of birth weight at parity $1, n=1279(2), n=945$ (3), $n=682$ (4), $n=442$ (5), $n=199$ (6), $n=104$ (7), $n=39$ (8), $n=23$ (9), $n=15$ (10) and $n=5$ (11). For Study 2, individual ewe body weights, body composition score and nutritional intake were not recorded consistently and not entered into the analysis.

A subset of 57 Study 2 ewes were analysed separately. In this group of ewes (Mule dam and Charrolais ram), both the maternal birth weight (born 2001) and the birth weight of the $F_{1}$ generation (born 2003 to a different Charrolais ram) were known and thus any transgenerational effect on birth weight could be examined together with the influence of a higher paternal input from Charrolais stock.

\section{Statistical analyses}

Study 1

All data are expressed as means \pm s.E.M. unless otherwise stated. The maternal influences on lamb birth weight were analysed by univariate general linear model with categorical data as fixed effects using SPSS v14 (SPSS, Inc., Chicago, IL, USA). Mixed model linear regression

Table 1 Total weight of diet calculated per ewe fed to group housed ewes in Study 2.

\begin{tabular}{|c|c|c|c|c|c|}
\hline \multirow[b]{2}{*}{$\begin{array}{l}\text { Weeks prior to term } \\
\text { Days gestation }\end{array}$} & \multicolumn{5}{|c|}{ Kilograms diet per ewe } \\
\hline & $\begin{array}{c}\mathbf{8} \\
(113-119)\end{array}$ & $\begin{array}{c}\mathbf{6} \\
(120-126)\end{array}$ & $\begin{array}{c}\mathbf{4} \\
(127-133)\end{array}$ & $\begin{array}{c}\mathbf{2} \\
(134-140)\end{array}$ & $\begin{array}{c}\mathbf{1} \\
(141-147)\end{array}$ \\
\hline \multicolumn{6}{|l|}{ Grass nuts } \\
\hline Singles & 0.20 & 0.20 & 0.40 & 0.40 & 0.40 \\
\hline Twins & 0.20 & 0.20 & 0.40 & 0.40 & 0.40 \\
\hline Triplets & 0.25 & 0.50 & 0.50 & 0.50 & 0.50 \\
\hline \multicolumn{6}{|l|}{ Concentrate } \\
\hline Singles & 0.10 & 0.25 & 0.25 & 0.25 & 0.25 \\
\hline Twins & 0.10 & 0.25 & 0.50 & 0.50 & 0.50 \\
\hline Triplets & 0.20 & 0.30 & 0.50 & 0.70 & 0.70 \\
\hline \multicolumn{6}{|l|}{ Total concentrate } \\
\hline Singles & 0.30 & 0.45 & 0.65 & 0.65 & 0.65 \\
\hline Twins & 0.30 & 0.45 & 0.90 & 0.90 & 0.90 \\
\hline Triplets & 0.45 & 0.80 & 1.00 & 1.20 & 1.20 \\
\hline
\end{tabular}


analysis (REML) was performed using Genstat v8. For the purposes of analysis, body condition score was ascribed as being low $(\leq 2)$, normal (2.5-3.5) or high $(\geq 4)$.

\section{Study 2}

Here, multilevel (mixed-effects) regression techniques were used as an exploratory tool to identify potential relationships between the response variable (birth weight) and the various candidate explanatory variables using MLWin (http://tramss.data-archive.ac.uk) developed at the Institute of Education, London. Comparison of fixed effects was performed using REML estimates. With such techniques, there is a clear risk of obtaining a false-positive result through the multiple tests being performed. To mitigate this risk, twin approaches of (1) using conservative significance levels within tests (1\%) and (2) partitioning the data into two sets; (a) a training set for model selection (348 ewes) and (b) a validation set (303 ewes) were employed. Models selected using the training sets were finally cross-checked against the validation set.

\section{Results}

\section{Study 1: The effect of maternal characteristics and nutrition on birth weight in the sheep}

\section{Maternal characteristics}

Initial observation of the total population of data indicated a significant effect of ewe weight on lamb weight $\left(r^{2}=0.37, t=7.30, P<0.001\right)$ with Welsh Mountain ewes generally being smaller (weight $45.5 \mathrm{~kg}$ (43.9-47.1) mean with 95\% Cl) than Mule ewes (weight $69.0 \mathrm{~kg}(67.4-70.6)$ mean with 95\% Cl). Using general linear modelling, with respect to birth weight for the whole population, significant explanatory factors were found to be litter size $(F=9.73, P<0.0001)$ and ewe weight ( $F=3.67, P<0.0001$; Fig. 1$)$ as expected. Given the relationship between ewe and lamb weights, the data were also analysed as fetal:maternal weight ratio to give a more accurate description of fetal growth per se. The effect of litter size on birth weight was strengthened $(F=18.5, P<0.0001)$, ewe weight remained a significant predictor and sex of the lamb became a significant explanatory variable $(F=9.37, P<0.0001$; Fig. 2B). Average population weights at birth for both breeds of sheep and both sexes are given in Table 2. Naturally, total litter weight (for example, combined weight of twin lambs) increased with increasing litter size $(F=104$, $P<0.0001)$, but there was a significant interaction between breed of sheep and total litter weight expressed relative to maternal weight, i.e. the proportional increase in litter size relative to the ewe was greater in Mule relative to Welsh ewes (Welsh sheep: singles, 9.4 $\pm 0.2 \%$; twins, $12.2 \pm 0.4 \%$ ewe weight; Mule ewes: singles, $7.9 \pm 0.3 \%$; twins, $14.3 \pm 0.3 \%$ ewe weight).

\section{Maternal nutrition}

Overall, energy intake during gestation had a significant influence on weight at birth $(P<0.001)$. Examining the estimated linear regression coefficients produced for each gestational period, with birth weight as the response variable, indicated no significant effects of maternal energy intake during early or mid-gestation, but a significant positive effect of late gestation nutrition $(+207 \pm 3 \mathrm{~g} / 1 \mathrm{M}$ ) increase in energy; $P<0.001)$ on lamb birth weight, when ewe weight and litter size were controlled for (since these were used to calculate the

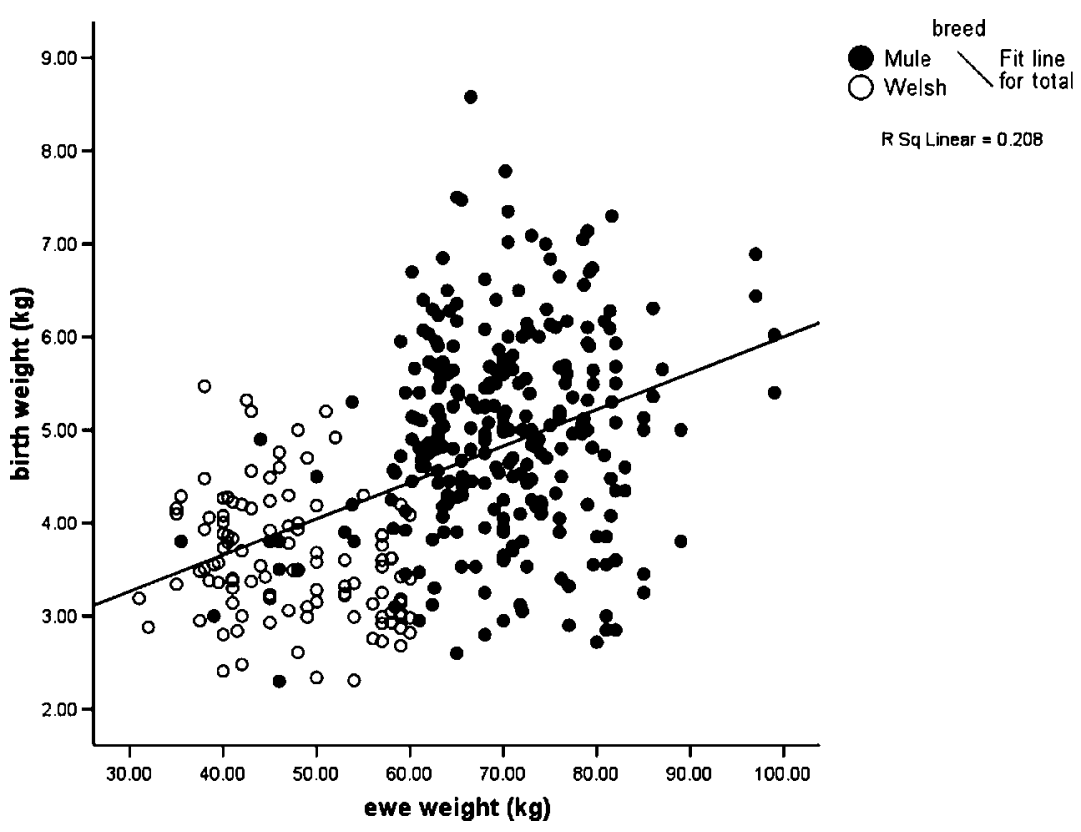

Figure 1 Relationship between ewe and lamb weight in Welsh Mountain and Mule sheep. Values are paired data points for Welsh Mountain $(O$, $n=59)$ and Mule (,$n=34)$ ewes and their singleton offspring. Linear regression indicated a significant effect of ewe weight on weight of the lamb $\left(F=100, P<0.001, r^{2}=0.20\right)$. 

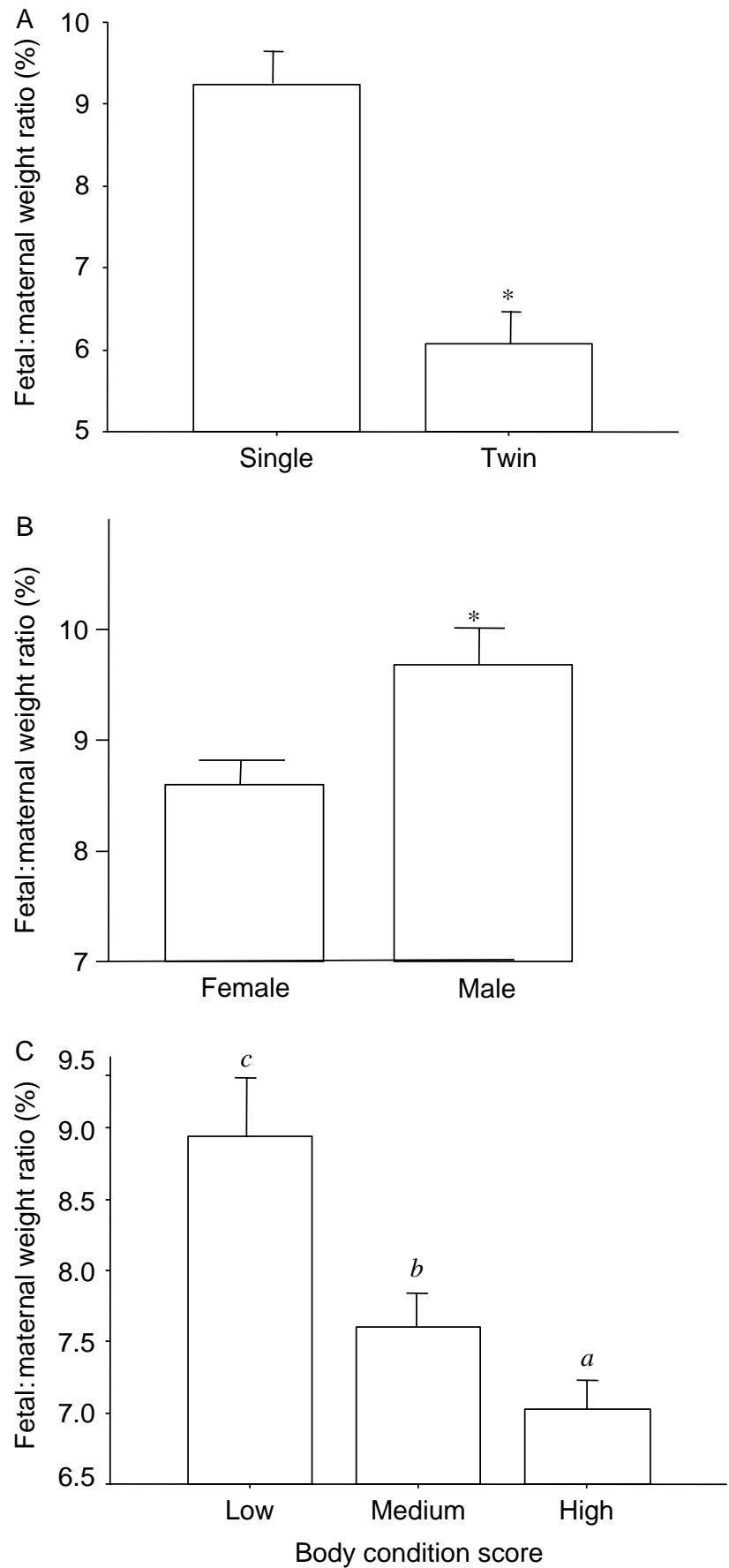

Figure 2 Fetal:maternal weight ratio (\%) of lambs at term split according to (A) singleton/twin, (B) male/female or (C) high/medium/low body condition score ewes. Values are mean \pm s.E.M. for individual data points of singleton $(n=95)$ and twin lambs $(n=50)$ and for low $(n=29)$, medium ( $n=122)$ or high $(n=15)$ body condition score of ewes at mating. See Materials and Methods for details. Statistical differences are, ${ }^{*} P<0.001$ singleton versus twin; male versus female. $C$, differing superscripts indicate statistical difference at $P<0.001$.

energy ration fed to the ewe). In addition, maternal body condition score prior to conception had a significant effect on birth outcome. Moving from a high ( $>3.5$ body condition score (BCS); birth weight, $3.59 \pm 0.19)$ to low
Table 2 Birth weights in Study 1 Welsh mountain and Mule ewes.

\begin{tabular}{lcrlr}
\hline & Welsh mountain & $\boldsymbol{n}$ & \multicolumn{1}{c}{ Mule ewes } & $\boldsymbol{n}$ \\
\hline Singleton male & $4.18 \pm 0.10^{*^{+}}$ & 10 & $5.38 \pm 0.29^{*^{+\ddagger}}$ & 10 \\
Singleton female & $3.65 \pm 0.10^{+}$ & 8 & $5.00 \pm 0.33^{\ddagger}$ & 9 \\
Twin male & $3.29 \pm 0.09$ & 7 & $5.24 \pm 0.10^{*^{\ddagger}}$ & 8 \\
Twin female & $3.15 \pm 0.08$ & 6 & $4.74 \pm 0.08^{\ddagger}$ & 6 \\
\hline
\end{tabular}

${ }^{*} P<0.05$ to females, ${ }^{\dagger} P<0.05$ to twins, ${ }^{\ddagger} P<0.05$ to Welsh mountain.

$(<2$; birth weight, $3.76 \pm 0.12)$ body condition score was associated with a significant increase in the fetal:maternal weight ratio $(P<0.001$; Fig. $2 \mathrm{C})$, which remained when ewe weight and other potential confounding variables were controlled for.

\section{Study 2: The effect of maternal characteristics on birth weight in commercially bred sheep}

A multilevel model was fitted to the data with the nested error term represented by ewe population included as a random effect. This hierarchical model was found to be a significantly better fit than a general linear regression model with a simple error term $(P<0.001)$. Thus with ewe as a grouping random effect, the following factors were determined as having a significant $(P<0.0001)$ effect on lamb birth weight, presented in order of the strength of effect; litter size, sex of the lamb, health of the lamb (i.e. survived $>3$ days or not), year of birth, parity of the ewe and whether the ewe had experienced two or more barren seasons prior to a successful pregnancy. Individual effect sizes are given in Table 3.

\section{Litter size}

The population mean weight of singles was $5.47 \pm 0.04$, twins $4.84 \pm 0.01$, triplets $4.22 \pm 0.02$ and quads $3.46 \pm 0.07 \mathrm{~kg}$. With $5.12 \pm 0.04 \mathrm{~kg}$ as the 2005 reference

Table 3 Individual effects on lamb weight in the sheep.

\begin{tabular}{lc}
\hline Individual effect & Effect size $(\mathrm{g})$ \\
\hline Litter size...* $^{*}$ & \\
Twin & $-692 \pm 40$ \\
Triplet & $-1.40 \pm 0.04$ \\
Quad & $-2.08 \pm 0.11$ \\
Year of birth & +97 to +555 \\
2 barren seasons & \\
Health (alive/dead) & $-769 \pm 60$ \\
Parity 1 & $-619 \pm 55$ \\
Parity 1+ & $+351 \pm 36$ \\
Lamb sex** & +0 to +300 \\
Late gestation energy intake & $+363 \pm 25$ \\
Fetal:maternal weight & $+207 \pm 3 \%$ \\
Ewe BCS...\# & $\%$ \\
Moderate (2.5-3.5) & $\%$ \\
High (3.5 & $-1.24 \pm 0.48$ \\
\end{tabular}

Individual effects were calculated using REML estimates \pm S.E.M.

* Relative to a singleton. ${ }^{\dagger}$ Relative to not barren or 1 barren period.

${ }^{\ddagger}$ Lamb that survived. **Relative to female lambs. "Relative to ewe in low body condition score (BCS) at mating. 
weight for singles, then twins were $-0.692 \pm 40 \mathrm{~kg}$, triplets $-1.40 \pm 0.04 \mathrm{~kg}$ and quads $-2.08 \pm 0.11 \mathrm{~kg}$ lighter. The population mean conceptus weight for singles was as above, for twins $9.68 \pm 0.02 \mathrm{~kg}$, triplets $12.6 \pm 0.07 \mathrm{~kg}$ and quads $13.23 \pm 0.27 \mathrm{~kg}$. Figure 3 illustrates the increase in weight of the products of conception with litter size. There was a greater chance of the pregnancy resulting in a singleton in primiparous pregnancies versus multiparous ewes ( 16.3 vs $6.8 \%$ by the fourth pregnancy), whereas litter size increased with increasing parity (e.g. triplet pregnancies doubled from the first $(15.3 \%)$ to fifth $(35.3 \%)$ pregnancy).

\section{Sex of lamb}

The population mean birth weight for male and female lambs was $4.92 \pm 0.01$ and $4.57 \pm 0.01 \mathrm{~kg}$ respectively. Males were, on average, $363 \pm 25 \mathrm{~g}$ larger than female lambs $(P<0.0001)$, which was maintained irrespective of male/male, female/female and male/female pairings (Table 4). The frequency distribution of females:males in the whole study population was 50.5:49.5\%. There was no effect on average birth weight of a male lamb being paired with a female lamb and vice versa.

\section{Lamb health}

The population average birth weight for lambs that survived or did not survive was $4.79 \pm 0.01$ and $3.99 \pm 0.05 \mathrm{~kg}$ respectively. On average, lambs that subsequently died within 3 days of birth were $619 \pm 55 \mathrm{~g}$

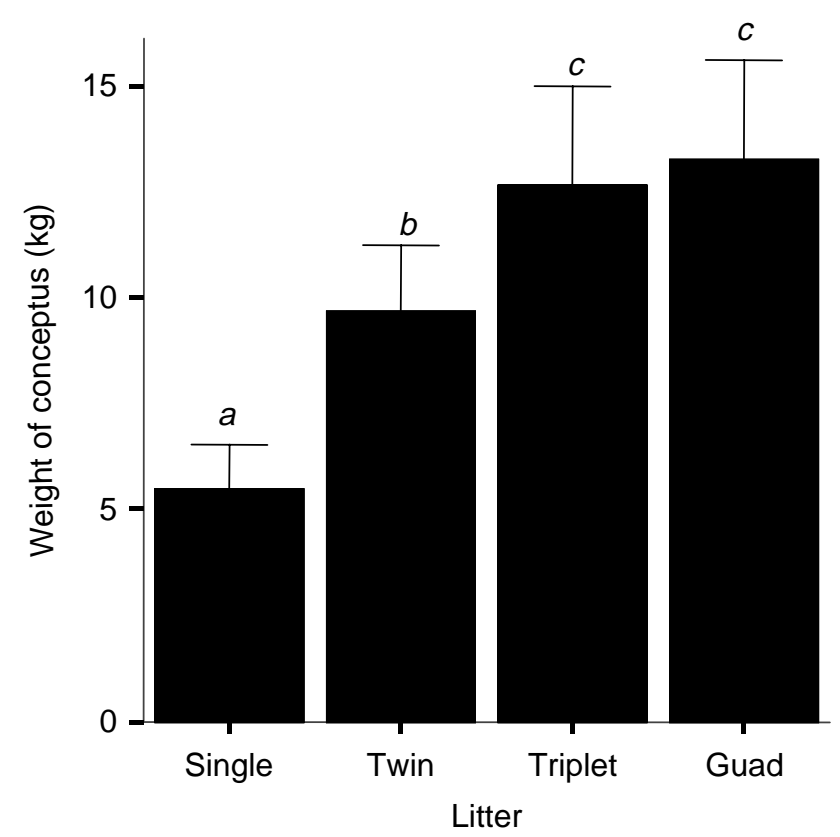

Figure 3 Total conceptus weight with increasing litter size. Values are mean \pm S.E.M. for individual singleton $(n=667)$, twin $(n=3456)$, triplet $(n=1098)$ and quad lambs $(n=75)$. Total litter weight significantly increased $(P<0.0001)$ with increasing litter size. A spline curve was fitted to the data.
Table 4 Twin lamb weights of differing sex pairings.

\begin{tabular}{lllc}
\hline & Lamb 1 $(\mathrm{kg})$ & Lamb 2 $(\mathrm{kg})$ & $\begin{array}{c}\text { Total litter } \\
\text { weight }(\mathrm{kg})\end{array}$ \\
\hline Sex pairings & & & \\
$\quad$ Male/male & $5.15 \pm 0.03^{*}$ & $5.11 \pm 0.03^{*}$ & $10.05 \pm 0.05^{*}$ \\
Female/female & $4.78 \pm 0.03$ & $4.76 \pm 0.03$ & $9.74 \pm 0.05$ \\
Male/female & $5.17 \pm 0.03^{*}$ & $4.79 \pm 0.03$ & $9.96 \pm 0.07^{*}$ \\
\hline
\end{tabular}

$* P<0.05$ to female/female twin lambs. For the male/female pairing, then Lamb 1 is male and Lamb 2 is female.

lighter than expected $(P<0.001)$. Of these lambs, the proportion dying increased with increasing litter size (e.g. singles $6.3 \%$, twins $5.2 \%$, triplets $9.8 \%$ and quads $20.8 \%$ ).

\section{Year of birth}

There was a significant effect of year on average birth weight of singleton lambs. Relative to the reference weight for singleton lambs in $2005(5.12 \pm 0.05 \mathrm{~kg})$, birth weights in previous years were: $+334 \pm 195$ (2004),

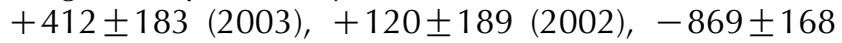
(2001), +22 215 (2000), $-822-168$ (1999), -275

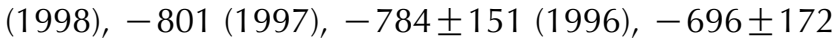
(1995), $-115 \pm 195$ (1994).

\section{Ewe parity}

With respect to the ewes first pregnancy (reference parity), multilevel modelling suggested a significant effect of parity $(P<0.0001)$ with average birth weight increasing up to the fourth pregnancy and thereafter declining (Fig. 4). The greatest increase was observed between the first and second pregnancy $(351 \pm 36 \mathrm{~g})$. There were no significant interaction effects with parity $\times$ litter size and parity $\times$ sex, i.e. the beneficial effect of parity on birth weight in sheep was not significantly different in twins or if the lambs were males/females.

\section{The effect of previously being barren}

If a ewe had been certified as barren for a single season, then there was no significant effect on subsequent pregnancies. However, if a ewe had been barren for two or more seasons immediately earlier, then birth weight in subsequent successful pregnancies was significantly reduced by an average of $769 \pm 23 \mathrm{~g}$.

\section{Transgenerational effects on birth weight}

In comparison to the population of Mule ewes described previously, the subset of ewe lambs mated with a Charrolais ram, for which both maternal and offspring birth weight data were available, the following coefficients were obtained: with respect to singletons (average birth weight $6.07 \pm 0.17$ ), twins were lighter by $-1.12 \pm 0.13 \mathrm{~kg}$, triplets by $-1.83 \pm 0.15 \mathrm{~kg}$ and quads by $-2.36 \pm 0.27 \mathrm{~kg}$; females were lighter than males by $630 \pm 79 \mathrm{~g}$; for every $1 \mathrm{~kg}$ increase in birth weight of the 

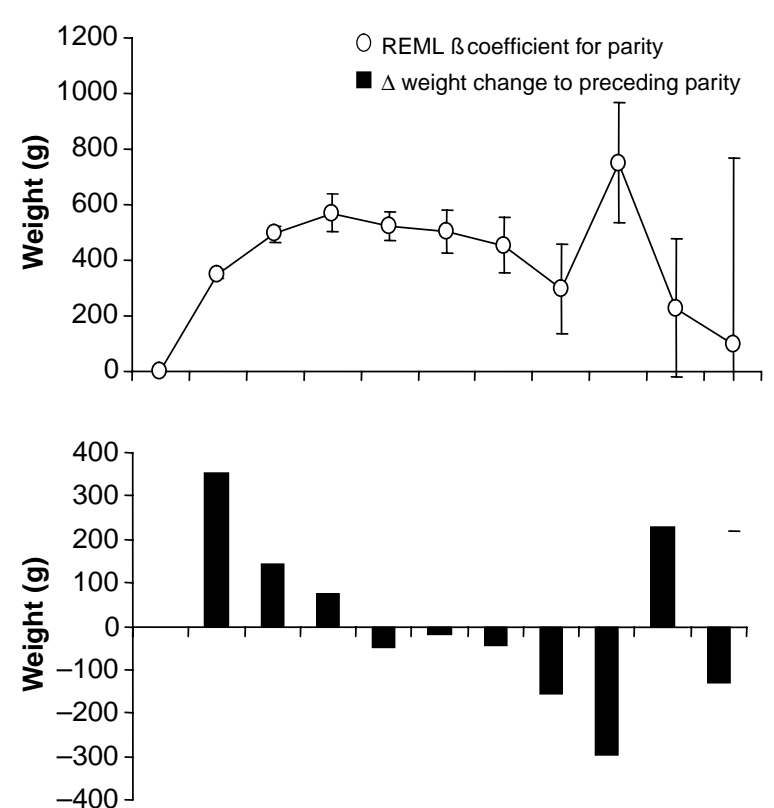

$\begin{array}{lllllllllll}1 & 2 & 3 & 4 & 5 & 6 & 7 & 8 & 9 & 10 & 11\end{array}$

\section{Parity}

Figure 4 Effect of parity on birth weight in Mule ewes. (A) Values represent the REML coefficients with S.E.M. or (B) $\Delta$, change in the coefficient from the preceding year with parity in grams. There was a significant increase in birth weight with parity up to the fourth pregnancy, thereafter weight declined. Excluding litters for which there was no birth weight data, there were: 2055 valid cases of birth weight at parity (1), $n=1279$ (2), $n=945$ (3), $n=682$ (4), $n=442$ (5), $n=199$ (6), $n=104$ (7), $n=39$ (8), $n=23$ (9), $n=15$ (10) and $n=5$ (11).

ewe, her offspring birth weight increased by $149 \pm 50 \mathrm{~g}$. In addition, for this group of ewes whom were born in 2001 and first had a pregnancy in 2003, the effect of year on birth weight was (relative to $2002 ; 4.96 \pm 0.23$ ), $+1.48 \pm 0.23$ (2003), + $1.85 \pm 0.23$ (2004), +1.93 \pm 0.23 (2005).

\section{Discussion}

Using the records of birth weight in lambs over 11 consecutive years in which all but environmental conditions (i.e. climate) have been relatively constant, and employing strict statistical methods, the present paper illustrates clearly the factors that are known to influence birth weight of the lamb at term (e.g. litter size and gender), other influences that have not been so clearly delineated previously (e.g. ewe weight and breed, parity of ewe, maternal nutrition and body condition of the ewe) and additional observations of marked interest (e.g. year of birth, maternal constraint of fetal growth, the effect of previous barren years).

\section{Litter size}

As in all placental mammals, the maternal uterine space has a finite capacity to gestate offspring, and as litter size increases individual birth weights decline. This effect is clearly represented by the present dataset and overrides all other effects on birth weight in both a highland and a lowland breed, e.g. twins were $87 \%$, triplets $75 \%$ and quads $62 \%$ average singleton weight in Mule ewes, broadly agreeing with the estimates of Robinson et al. (1977). The effect reflects, in part, (1) the physiological capacity for the mother to adequately supply the products of conception with metabolic substrate, (2) the physical capacity of the mother to bear multiple litters, (3) mechanical forces in differing areas of the uterus (i.e. body of uterus versus uterine horn) and (4) fetal genotypic effects. It is likely that all the above effects are interrelated and an umbrella term has been suggested, 'maternal constraint of fetal growth' (Gluckman \& Hanson 2004). Our dataset confirms that fetal growth is limited in certain circumstances, e.g. in nulliparous and multiple pregnancies. Indeed, the error term for birth weight decreased with increasing litter size, suggesting that the reduced uterine space limits variance in birth weight. The suggestion that maternal constraint per se operates in all pregnancies and therefore has longer term consequences in all offspring (Gluckman \& Hanson 2004) is difficult to reconcile with the present, and other twin studies in man (Bleker et al. 1979, Baird et al. 2001, Christensen et al. 2001, de Geus et al. 2001, ljzerman et al. 2002). Alternatively, we suggest that maternal constraint is indeed a significant physio-mechanical factor influencing prenatal growth in litter bearing pregnancies, but it is not constant. In singleton pregnancies from multiparous ewes, maternal constraint is barely evident and fetal growth is limited only by fetal genotype - itself conditioned by evolutionary factors (Kuzawa 2005). Using the present data to illustrate, average singleton weight in Mule ewes is $\sim 5.5 \mathrm{~kg}$ but a triplet/quad bearing uterus accommodates $\sim 14 \mathrm{~kg}$ conceptus. Therefore, the maternal environment, including varying caruncular recruitment, cannot offer any significant constraint on singleton fetal growth after the first pregnancy. Rather, fetal genotype has the overriding influence, e.g. a $10 \mathrm{~kg}$ singleton will lead to dystocia and both offspring and mother may well die as a result. Thus, over time, genes promoting excessive fetal growth in an environment that can cope, i.e. singleton pregnancies have become tempered. However, in certain circumstances, these growthpromoting genes may be overexpressed; for example, as occurs in large offspring syndrome (Sinclair et al. 2000). On the other hand, low birth weight lambs, whilst enjoying an easy extra uterine passage, are more susceptible to neonatal morbidity and mortality. Therefore, a reverse J-shaped curve exists between neonatal mortality and birth weight not only in sheep (Fraser \& Stamp 1987) but also, in theory, in all other placentals. A theoretical 'optimal' weight must therefore exist in all species and in all cases of polytocy, where these opposing influences are balanced. To illustrate maternal 
genotype $\times$ litter interactions on birth weight, the percentage increase in conceptus weight relative to maternal weight from a singleton to twin pregnancy in the highland Welsh Mountain sheep was one-half that observed in the lowland Mule ewe (3 vs 7\%).

\section{Gestational nutrition}

The relationship between maternal nutrition and birth weight has been investigated thoroughly in the sheep. In general, the studies have been agriculturally biased to determine productive efficiency in sheep, i.e. to achieve maximal output (lambing percentage) with minimal input (feeding regimes and husbandry; Russel 1971, Russel \& Foot 1973, Robinson 1977, Mellor \& Matheson 1979). Recently, many nutritional studies in sheep (Heasman et al. 2000, Bloomfield et al. 2003, Budge et al. 2003, Gardner et al. 2004, Gopalakrishnan et al. 2004, McMillen et al. 2004, Gardner et al. 2005) have focussed upon the central role of birth weight to the Developmental Origins of Adult Health and Disease hypothesis (Barker et al. 1993). However, the role of low birth weight per se as a predictor of later disease has been rightly questioned (Huxley et al. 2002). Birth weight is an easily measured and available proxy for the quantity of fetal growth achieved by term, but says little about the quality of that growth. In large-scale human epidemiological studies, it is a very useful measure, but recent studies are beginning to highlight more qualitative aspects of fetal and neonatal growth that serve as better predictors for likely disease progression, e.g. maternal metabolism during pregnancy (Duggleby \& Jackson 2002) or neonatal growth acceleration (Barker et al. 2005). Nevertheless, birth weight remains an important measure given its relationship to neonatal morbidity and mortality. In deriving feeding standards for sheep, it is assumed that the Agricultural and Food Research Council (AFRC 1993) based their calculations on energy conversion efficiency in sheep, i.e. what is the minimum energy requirement to produce an appropriately sized lamb $(\sim 4.5 \mathrm{~kg})$, but this may not necessarily meet the overall metabolic demands of the pregnant ewe; some weight is expected to be lost during gestation. In the present study, maternal energy intake from early to midgestation had little influence on lamb birth weight, but late gestation intake was positively associated with weight at term, not surprising since absolute fetal growth is greatest at this time. The lack of effect of early-mid-gestation intake is most likely through maternal 'buffering'; that is, the response is dependent on maternal pre-pregnancy condition. Indeed, maternal body condition at mating - a reflection of her energy intake over at least the 6-8 weeks prior to conception - had a significant effect on the birth weight of her lamb. Taken together, therefore, it would appear that maternal body condition prior to pregnancy and late gestational energy intake are most important in terms of birth weight in sheep. Based on the present data, we also agree with Robinson et al. (1977), that only relatively severe late gestational undernutrition will significantly reduce birth weight, i.e. $>500 \mathrm{~g}$, in the sheep. It is of interest that the mothers own birth weight had a positive influence on her offspring's birth weight in this study, as observed previously (Bradford 1972, Brooks et al. 1995). Whether this effect continues down further generations is not known, but it has been speculated that the effect may well continue down the matrilineal lineage (i.e. through female offspring only; Kuzawa 2005).

\section{Parity}

In many larger scale human epidemiological studies, parity is often added as a covariate in the analysis, although the actual effect of increasing parity on birth weight, for example, is rarely if ever acknowledged. These studies are also often complicated by external confounding factors that may influence birth weight. However, one study has shown that, with all other factors to their knowledge being equal, there is a $136 \mathrm{~g}$ increase in weight on average from the first to the second pregnancy (Wilcox et al. 1996). In the present study, the equivalent effect size was $\sim 351 \mathrm{~g}$. The threefold increase most likely reflects the use of a prolific sheep breed and that the dataset is relatively controlled from year-to-year. A first pregnancy leaves a 'physiological imprint' in the uterus, for example, increased vascularisation (Khong et al. 2003), and enables greater blood volume expansion during the second pregnancy (Campbell \& MacGillivray 1984) - each of which will facilitate relatively greater fetal growth in subsequent pregnancies. In this study, it is clear that this improvement, perhaps through these very mechanisms, continues up to the fourth pregnancy but then begins to decline. Whether the decline in the relative growth-promoting effect of previous pregnancies after the fourth delivery reflects a relative reduction in these mechanisms or increased uterine scar tissue and a reduction in the surface area for exchange (Stegeman 1974) cannot be determined. The effect of parity on birth weight is completely absent in ewes bearing triplets, demonstrating how physio-mechanical constraint within the uterus overrides other physiological factors when multiple young are present. Within this cohort of sheep, increasing parity also represents increasing age and age, of itself, has been suggested as an independent factor influencing birth weight and neonatal outcome (Hemminki \& Gissler 1996). We are unable to adequately address this question with the present cohort, but have preliminary data from small groups $(n=15-20)$ of old and young primiparous ewes and report no major effects on birth weight of age per se (old ewes ( $2-3$ years), $4.2 \pm 0.4$ versus young ewes ( 1 year) $4.5 \pm 0.4 \mathrm{~kg}$ ).

\section{Barrenness}

Regarding the effect that two previous barren seasons, but not one, significantly reduces birth weight of subsequent 
offspring is important information and most likely underpins why ewes are not kept in the flock if such an occurrence happens. The underlying mechanisms for these are unknown but may relate to the causes of being barren, e.g. altered hormone profiles or impaired ovulatory function.

\section{Sex of the lamb}

It is interesting, but not unexpected (Robinson et al. 1977, de Zegher et al. 1999, Cruickshank et al. 2005), that on balance male offspring are larger $(\sim 300-400 \mathrm{~g})$ than female offspring at birth in the sheep. Clearly, the presence of a Y-chromosome and the products of srygene activation, e.g. androgens and mullerian-inhibitor substance (Haqq et al. 1994), has sex-specific effects on fetal growth. Males appear to grow faster than respective females in utero (de Zegher et al. 1999, Loos etal. 2001). We observed no effect of mixed-sex twin pairings on the average birth weight of each sex as has been previously reported (Fraser \& Stamp 1987) and the sex ratio for the whole dataset reflects that observed in many mammalian populations, i.e. slightly favouring males rather than females (50.5:49.5\%).

\section{Effect of year of birth}

Finally, and unexpectedly, year of birth had a significant effect on overall birth weight, producing shifts in singleton birth weight, on average, of up to $1.0 \mathrm{~kg}$. These effects occurred despite no obvious difference in flock management, nutrition and other factors known to affect birth weight in the sheep. Therefore, the supposition is that the external environment or climate before or during pregnancy may have influenced overall birth weight. Such a remarkable effect has been observed recently in a human cohort in Bristol (Lawlor et al. 2005) and it is known that season of birth can influence weight at term (McGrath et al. 2005). For the present dataset, this hypothesis can be tested as accurate climatic records exist over the time of the study. However, this analysis is well beyond the remit of the present study and is likely to be very complex given the long duration of gestation. Alternatively, there is clear potential for paternal genotype to influence weight at birth in the sheep. However, other studies have shown little paternal influence on birth weight (Brooks et al. 1995) and in this cohort the same breed of ram was used throughout. However, variance due to individual ram effects could not be controlled for in the present study.

In conclusion, the present paper shows that the single greatest effect on birth weight was litter size, with additional analysis yielding interesting insights into the nature of 'maternal constraint of growth'. Further, significant effects on birth weight in these cohorts were found to be year of birth, sex of the lamb, whether the ewe had been barren in two consecutive years and whether the lamb survived or not. Maternal body composition prior to pregnancy and maternal nutrition during late gestation also had significant effects on birth weight in the sheep. The results of the present study have practical implications not only for the husbandry of the sheep as an agricultural, economical commodity but also, and importantly, for the increased knowledge of factors that significantly influence variation in birth weight; as birth weight itself has become a significant predictor of later health outcomes.

\section{Acknowledgements}

The authors wish to acknowledge Prof. Fiona Broughton-Pipkin for initial discussion of the dataset, Mark Edmondson-Jones and Graham Warren (Information Services, University of Nottingham), who developed the statistical models used in the present manuscript, the staff of the University of Nottingham's farm (Mr Jonathon Newnham and William Donger), who catalogued the data and the staff of the Joint Animal Breeding Unit, University of Nottingham for assistance with the feeding trials. DSG is supported by a British Heart Foundation Lectureship (BS/03/001) and the nutrition trials in Study 1 were supported by the British Heart Foundation and DEFRA. The authors declare that there is no conflict of interest that would prejudice the impartiality of this scientific work.

\section{References}

AFRC 1993 Energy and protein requirements of ruminants, An Advisory Manual Prepared by the AFRC Technical Committee on Responses to Nutrients, Oxford: CAB International.

Alexander G 1974 Birth weight of lambs: influences and consequences. In Size at Birth, pp 215-245. Eds K Elliot \& J Knight. Amsterdam: Elsevier.

Armitage JA, Khan IY, Taylor PD, Nathanielsz PW \& Poston L 2004 Developmental programming of metabolic syndrome by maternal nutritional imbalance; how strong is the evidence from experimental models in mammals? Journal of Physiology 561 355-377.

Baird J, Osmond C, MacGregor A, Snieder H, Hales CN \& Phillips DI 2001 Testing the fetal origins hypothesis in twins: the Birmingham twin study. Diabetologia 44 33-39.

Barker DJ, Gluckman PD, Godfrey KM, Harding JE, Owens JA \& Robinson JS 1993 Fetal nutrition and cardiovascular disease in adult life. Lancet 341 938-941.

Barker DJ, Osmond C, Forsen TJ, Kajantie E \& Eriksson JG 2005 Trajectories of growth among children who have coronary events as adults. New England Journal of Medicine 353 1802-1809.

Black JL 1983 Growth and development of lambs. In Sheep Production, pp 21-58. Ed. W Horesign. London: Butterworths.

Bleker OP, Breur W \& Huidekoper BL 1979 A study of birth weight, placental weight and mortality of twins as compared to singletons. British Journal of Obstetrics and Gynaecology 86 111-118.

Bloomfield FH, Oliver MH, Giannoulias CD, Gluckman PD, Harding JE \& Challis JR 2003 Brief undernutrition in late-gestation sheep programs the hypothalamic-pituitary-adrenal axis in adult offspring. Endocrinology 144 2933-2940.

Bradford GE 1972 The role of maternal effects in animal breeding. VII. Maternal effects in sheep. Journal of Animal Science 35 1324-1334.

Bradford GE, Taylor CS, Quirke JF \& Hart R 1974 An egg transfer study of litter size, birth weight and lamb survival. Animal Production 18 249-263.

Brooks AA, Johnson MR, Steer PJ, Pawson ME \& Abdalla HI 1995 Birth weight: nature or nurture? Early Human Development 42 29-35.

Budge H, Dandrea J, Mostyn A, Evens Y, Watkins R, Sullivan C, Ingleton P, Stephenson T \& Symonds ME 2003 Differential effects of 
fetal number and maternal nutrition in late gestation on prolactin receptor abundance and adipose tissue development in the neonatal lamb. Pediatric Research 53 302-308.

Campbell DM \& MacGillivray I 1984 The importance of plasma volume expansion and nutrition in twin pregnancy. Acta Geneticae Medicae et Gemellologiae (Roma) 33 19-24.

Christensen K, Wienke A, Skytthe A, Holm NV, Vaupel JW \& Yashin AI 2001 Cardiovascular mortality in twins and the fetal origins hypothesis. Twin Research 4 344-349.

Cogswell ME \& Yip R 1995 The influence of fetal and maternal factors on the distribution of birthweight. Seminars in Perinatology 19 222-240.

Cruickshank JK, Mzayek F, Liu L, Kieltyka L, Sherwin R, Webber LS, Srinavasan SR \& Berenson GS 2005 Origins of the 'black/white' difference in blood pressure: roles of birth weight, postnatal growth, early blood pressure, and adolescent body size: the Bogalusa heart study. Circulation 111 1932-1937.

Dandrea J, Wilson V, Gopalakrishnan G, Heasman L, Budge H, Stephenson T \& Symonds ME 2001 Maternal nutritional manipulation of placental growth and glucose transporter 1 (GLUT-1) abundance in sheep. Reproduction 122 793-800.

de Geus EJ, Posthuma D, Ijzerman RG \& Boomsma DI 2001 Comparing blood pressure of twins and their singleton siblings: being a twin does not affect adult blood pressure. Twin Research 4 385-391.

de Zegher F, Devlieger H \& Eeckels R 1999 Fetal growth: boys before girls. Hormone Research 51 258-259.

Dickinson AG, Hancock JL, Hovell GJR, Taylor CS \& Wiener G 1962 The size of lambs at birth-a study involving egg transfer. Animal Production 4 64-79.

Duggleby SL \& Jackson AA 2002 Higher weight at birth is related to decreased maternal amino acid oxidation during pregnancy. American Journal of Clinical Nutrition 76 852-857.

Edwards LJ \& McMillen IC 2002 Periconceptional nutrition programs development of the cardiovascular system in the fetal sheep. American Journal of Physiology Regulatory, Integrative and Comparative Physiology 283 R669-R679.

Fahey AJ, Brameld JM, Parr T \& Buttery PJ 2005 The effect of maternal undernutrition before muscle differentiation on the muscle fiber development of the newborn lamb. Journal of Animal Science $\mathbf{8 3}$ 2564-2571.

Fraser A \& Stamp JY 1987 Sheep Husbandry and Diseases, New York: Sheridan House Inc.

Gardner DS, Pearce S, Dandrea J, Walker R, Ramsay MM, Stephenson T \& Symonds ME 2004 Peri-implantation undernutrition programs blunted angiotensin II evoked baroreflex responses in young adult sheep. Hypertension 43 1290-1296.

Gardner DS, Tingey K, Van Bon BW, Ozanne SE, Wilson V, Dandrea J, Keisler DH, Stephenson T \& Symonds ME 2005 Programming of glucose-insulin metabolism in adult sheep after maternal undernutrition. American Journal of Physiology. Regulatory, Integrative and Comparative Physiology 289 R947-R954.

Gatford KL, De Blasio MJ, Thavaneswaran P, Robinson JS, McMillen IC \& Owens JA 2004 Postnatal ontogeny of glucose homeostasis and insulin action in sheep. American Journal of Physiology. Endocrinology and Metabolism 286 E1050-E1059.

Giussani DA, Forhead AJ, Gardner DS, Fletcher AJ, Allen WR \& Fowden AL 2003 Postnatal cardiovascular function after manipulation of fetal growth by embryo transfer in the horse. Journal of Physiology 547 67-76.

Gluckman PD \& Hanson MA 2004 Maternal constraint offetal growth and its consequences. Seminars in Fetal \& Neonatal Medicine 9 419-425.

Godfrey KM \& Barker DJ 2001 Fetal programming and adult health. Public Health Nutrition 4 611-624.

Gopalakrishnan GS, Gardner DS, Rhind SM, Rae MT, Kyle CE, Brooks AN, Walker RM, Ramsay MM, Keisler DH, Stephenson T \& Symonds ME 2004 Programming of adult cardiovascular function after early maternal undernutrition in sheep. American Journal of Physiology. Regulatory, Integrative and Comparative Physiology 287 R12-R20.

Gopalakrishnan GS, Gardner DS, Dandrea J, Langley-Evans SC, Pearce S, Kurlak LO, Walker RM, Seetho IW, Keisler DH, Ramsay MM,
Stephenson T \& Symonds ME 2005 Influence of maternal prepregnancy body composition and diet during early-mid pregnancy on cardiovascular function and nephron number in juvenile sheep. British Journal of Nutrition 94 938-947.

Haqq CM, King CY, Ukiyama E, Falsafi S, Haqq TN, Donahoe PK \& Weiss MA 1994 Molecular basis of mammalian sexual determination: activation of Mullerian inhibiting substance gene expression by SRY. Science 266 1494-1500.

Heasman L, Clarke L, Firth K, Stephenson T \& Symonds ME 1998 Influence of restricted maternal nutrition in early to mid gestation on placental and fetal development at term in sheep. Pediatric Research 44 546-551.

Heasman L, Brameld J, Mostvn A, Budge H, Dawson J, Buttery P, Stephenson T \& Symonds ME 2000 Maternal nutrient restriction during early to mid gestation alters the relationship between insulinlike growth factor I and bodyweight at term in fetal sheep. Reproduction, Fertility and Development 12 345-350.

Hemminki E \& Gissler M 1996 Births by younger and older mothers in a population with late and regulated childbearing: Finland 1991. Acta Obstetricia et Gynecologica Scandinavica 75 19-27.

Huxley R, Neil A \& Collins R 2002 Unravelling the fetal origins hypothesis: is there really an inverse association between birthweight and subsequent blood pressure? Lancet 360 659-665.

ljzerman RG, Boomsma DI \& Stehouwer CD 2002 Twins and the fetal origins hypothesis. Lancet $\mathbf{3 6 0} 2075$.

Khong TY, Adema ED \& Erwich JJ 2003 On an anatomical basis for the increase in birth weight in second and subsequent born children. Placenta 24 348-353.

Kuzawa CW 2005 Fetal origins of developmental plasticity: are fetal cues reliable predictors of future nutritional environments? American Journal of Human Biology 17 5-21.

Lawlor DA, Leon DA \& Davey SG 2005 The association of ambient outdoor temperature throughout pregnancy and offspring birthweight: findings from the Aberdeen Children of the 1950s cohort. An International Journal of Obstetrics and Gynaecology 112 647-657.

Loos RJ, Derom C, Eeckels R, Derom R \& Vlietinck R 2001 Length of gestation and birthweight in dizygotic twins. Lancet 358 560-561.

McGrath JJ, Barnett AG \& Eyles DW 2005 The association between birth weight, season of birth and latitude. Annals of Human Biology 32 547-559.

McMillen IC, Muhlhausler BS, Duffield JA \& Yuen BS 2004 Prenatal programming of postnatal obesity: fetal nutrition and the regulation of leptin synthesis and secretion before birth. Proceedings of the Nutrition Society 63 405-412.

Mellor DJ \& Matheson IC 1979 Daily changes in the curved crownrump length of individual sheep fetuses during the last 60 days of pregnancy and effects of different levels of maternal nutrition. Quarterly Journal of Experimental Physiology and Cognate Medical Sciences 64 119-131.

NIH 1985 Principles of Laboratory Animal Care, NIH Publication, pp. 99-158. NIH: Bethesda, Maryland, USA.

Ong KK, Preece MA, Emmett PM, Ahmed ML \& Dunger DB 2002 Size at birth and early childhood growth in relation to maternal smoking, parity and infant breast-feeding: longitudinal birth cohort study and analysis. Pediatric Research 52 863-867.

Robinson JJ 1977 The influence of maternal nutrition on ovine foetal growth. Proceedings of the Nutrition Society 36 9-16.

Robinson JJ, Mcdonald I, Fraser C \& Crofts RMJ 1977 Studies on reproduction in prolific ewes. 1. Growth of products of conception. Journal of Agricultural Science 88 539-552.

Russel AJ 1971 Relationships between energy intake and productivity in hill sheep. Proceedings of the Nutrition Society 30 197-204.

Russel AJ \& Foot JZ 1973 The effect of level of nutrition at two stages of pregnancy on the performance of primiparous ewes. Proceedings of the Nutrition Society 32 27A-28A.

Russel AJF, Doney JM \& Gunn RG 1969 Subjective assessment of body fat in live sheep. Journal of Agricultural Science 72 451-454. 
Sinclair KD, Young LE, Wilmut I \& McEvoy TG 2000 In utero overgrowth in ruminants following embryo culture: lessons from mice and a warning to men. Human Reproduction 15 (Supplement 5) 68-86.

Stegeman JHJ 1974 Placental development in the sheep and its relation to fetal development: a qualitative and quantitative anatomic and histologic study. Contributions to Zoology 44 3-73.

Wallace LR 1948 The growth of lambs before and after birth in relation to the level of nutrition. Journal of Agricultural Science $\mathbf{3 8}$ 243-302.

Wallace JM, Aitken RP \& Cheyne MA 1996 Nutrient partitioning and fetal growth in rapidly growing adolescent ewes. Journal of Reproduction and Fertility 107 183-190.
Walton A \& Hammond J 1938 The maternal effects on growth and conformation in Shire horse-Shetland pony crosses. Proceedings of the Royal Society of London 125 311-335.

Wilcox MA, Chang AM \& Johnson IR 1996 The effects of parity on birthweight using successive pregnancies. Acta Obstetricia et Gynecologica Scandinavica 75 453-459.

Received 24 May 2006

First decision 22 June 2006

Revised manuscript received 18 August 2006

Accepted 29 August 2006 